\title{
Políticas Públicas e Desenvolvimento Territorial: uma análise do Programa Nacional de Alimentação Escolar nos municípios de Dracena e Regente Feijó - SP
}

Public Policies and Territorial Development: an analysis of the Programa Nacional de Alimentação Escolar in the municipalities of Dracena and Regente Feijó - SP

\author{
Políticas Públicas y Desarrollo Territorial: un análisis del Programa Nacional de \\ Alimentação Escolar en los municipios de Dracena y Regente Feijó - SP
}

\author{
Ellen Tamires Pedriali Colnago ${ }^{1}$
}

Rosangela Aparecida de Medeiros Hespanhol ${ }^{2}$

\begin{abstract}
RESUMO: A descentralização política e administrativa, ocorrida na década de 1990, associada à eminência da abordagem territorial, modificaram as condições de execução de políticas públicas, como o PNAE. Nos anos 2000, com a incorporação dos agricultores familiares como fornecedores da alimentação escolar, esse programa ganhou maior relevância social. Buscando apresentar a operacionalização do Programa Nacional de Alimentação Escolar (PNAE), nos municípios de Dracena e Regente Feijó, localizados no Estado de São Paulo, foram adotados como procedimentos metodológicos revisão da literatura em fontes bibliográficas, realização de entrevistas com os atores sociais, formadores do arranjo institucional, necessário para o funcionamento do PNAE, e aplicação de questionários com os agricultores familiares participantes do programa. Em Dracena e Regente Feijó, ocorre a participação do Setor da Alimentação Escolar e dos agrônomos pertencentes às Casas de Agricultura para o desenvolvimento do programa e a inserção da agricultura familiar. Contudo, a atuação do Conselho de Alimentação Escolar (CAE), não ocorre da mesma forma. Em Dracena, ele é mais atuante que o de Regente Feijó, assim como a participação dos produtores rurais no primeiro município através de uma cooperativa permite a inserção dos agricultores familiares em outras políticas públicas, situação que não ocorre no município de Regente Feijó, pois os produtores participam do PNAE por meio de um grupo informal, tendo neste programa a única alternativa de comercialização de seus produtos.
\end{abstract}

PALAVRAS-CHAVES: Desenvolvimento territorial. Descentralização. Arranjos institucionais. PNAE. Agricultura familiar.

ABSTRACT: Political and administrative decentralization, which took place in the 1990s, associated to the eminence of the territorial approach, modified the conditions for the execution of public policies, such as the PNAE. In the 2000s, with the incorporation of family farmers as providers of school feeding, this program gained greater social relevance. Aiming to present the operation of the National

\footnotetext{
${ }^{1}$ Programa de Pós-Graduação da FCT-UNESP, campus de Presidente Prudente. Rua Roberto Simonsen, 305 Centro Educacional - P. Prudente/SP - CEP 19060-900. E-mail: ellencolnago@hotmail.com.

${ }^{2}$ Programa de Pós-Graduação da FCT-UNESP, campus de Presidente Prudente. Rua Roberto Simonsen, 305 Centro Educacional - P. Prudente/SP - CEP 19060-900. E-mail: rosangela.hespanhol@unesp.br.
} 
School Feeding Program (PNAE), in the municipalities of Dracena and Regente Feijó, located in the State of São Paulo, were adopted as methodological procedures, literature review in bibliographical sources, interviews with social actors, formators of the institutional arrangement necessary for the operation of the PNAE, and the application of questionnaires with the family farmers participating in the program. In Dracena and Regente Feijó, there is the participation of the School Feeding Sector and the agronomists belonging to the Houses of Agriculture for the development of the program and the insertion of family agriculture. However, the performance of the School Feeding Council (CAE) does not occur in the same way. In Dracena, he is more active than Regente Feijó, as the participation of rural producers in the first municipality through a cooperative allows the insertion of family farmers in other public policies, a situation that does not occur in the municipality of Regente Feijó, since the producers participate in the PNAE through an informal group, having in this program the only alternative to market their products.

KEYWORDS: Territorial development. Decentralization. Institutional arrangements. PNAE. Family agriculture.

RESUMEN: La descentralización política y administrativa, ocurrida en la década de 1990, asociada a la eminencia del abordaje territorial, modificaron las condiciones de ejecución de políticas públicas, como el PNAE. En los años 2000, con la incorporación de los agricultores familiares como proveedores de la alimentación escolar, ese programa ganó mayor relevancia social. En los municipios de Dracena y Regente Feijó, ubicados en el Estado de São Paulo, fueron adoptados como procedimientos metodológicos, revisión de la literatura en fuentes bibliográficas, realización de entrevistas con los actores sociales, formadores del arreglo institucional, necesario para el funcionamiento del PNAE, y aplicación de cuestionarios con los agricultores familiares participantes del programa. En Dracena y Regente Feijó, ocurre la participación del Sector de la Alimentación Escolar y de los agrónomos pertenecientes a las Casas de Agricultura para el desarrollo del programa y la inserción de la agricultura familiar. Sin embargo, la actuación del Consejo de Alimentación Escolar (CAE), no ocurre de la misma forma. En Dracena, él es más activo que el de Regente Feijó, así como la participación de los productores rurales en el primer municipio a través de una cooperativa permite la inserción de los agricultores familiares en otras políticas públicas, situación que no ocurre en el municipio de Regente Feijó, los productores participan en el PNAE a través de un grupo informal, teniendo en este programa la única alternativa de comercialización de sus productos.

PALABRAS-CLAVE: Desarrollo territorial. Descentralización. Arreglos institucionales. PNAE. Agricultura familiar.

\section{INTRODUÇÃO}

A atuação do Estado brasileiro no que tange à implementação de políticas públicas teve alterações na década de 1990, em razão primeiramente do processo de descentralização política e administrativa, resultante da Constituição Federal de 1988, e, posteriormente, com a introdução da abordagem do desenvolvimento territorial, que ocorreu mais efetivamente nos anos 2000.

No que se refere ao processo de descentralização, este engendrou alterações na operacionalização das políticas públicas, uma vez que os municípios passaram a ser responsáveis por executar determinados programas do governo federal, de modo que novos 
atores sociais emergiram como figuras importantes para a implementação de programas na escala local, possibilitando a formação de arranjos institucionais para a sua execução.

A própria expansão da abordagem do desenvolvimento territorial no Brasil, no final dos anos 1990, relaciona-se diretamente ao contexto político e econômico vivenciado neste período, em que, com o processo de descentralização e a crise financeira, o Estado perde sua capacidade de financiar políticas públicas que visavam ao crescimento econômico (ALVES, 2003; HESPANHOL, 2010). Desse modo, para atender as exigências das instituições internacionais, como o (FMI) - Fundo Monetário Internacional, as políticas de desenvolvimento territorial são estimuladas no Brasil, em especial as voltadas para dinamizar os espaços rurais, por meio de estratégias que possibilitassem o desenvolvimento rural, e, em especial, se direcionassem para os agricultores familiares.

Para que essas políticas com enfoque territorial fossem operacionalizadas, era necessária a participação da sociedade na gestão de projetos em âmbito local, de modo que integrassem os espaços urbanos e rurais e possibilitassem o desenvolvimento, como foi ditado aos países subdesenvolvidos pelas agências multilaterais, em especial o Banco Mundial (ALVES; GUIVANT, 2010; WANDERLEY; FAVARETO, 2013).

O Brasil seguiu à risca essa "receita" em busca de novos resultados para a atuação do Estado frente ao cenário político e econômico dos anos 1990, dando continuidade ao enfoque territorial, na implementação de políticas públicas, nos anos 2000.

Assim, programas governamentais da esfera federal sofreram mudanças com o processo de descentralização e a adoção da abordagem do desenvolvimento territorial, entre eles o Programa Nacional de Alimentação Escolar (PNAE). Estabelecido como um programa voltado para atender a alimentação escolar, criado na década de 1950, o PNAE, nos anos 1990, deixa de ter suas atividades totalmente controladas pelo governo federal, sendo a gestão do programa transferida para os municípios.

Nos anos 2000, a partir da institucionalização da lei n 11.947/2009 (BRASIL, 2009), o governo federal passa a considerar a agricultura familiar como um dos públicos a serem atendidos pelo programa, por meio da possibilidade de aquisição de gêneros alimentícios desse segmento social para atender a alimentação escolar das unidades de ensino.

As transformações do programa nas décadas de 1990 e 2000 passaram a requerer, deste modo, uma articulação na escala local (municipal) entre os atores sociais para executá-lo, a partir da formação de arranjos institucionais.

Ao problematizarmos o funcionamento do PNAE em duas realidades empíricas, ou seja, os municípios de Dracena e Regente Feijó, localizados no Estado de São Paulo (figura 1), é possível observar a importância de se constituir os arranjos institucionais locais para o desenvolvimento do programa, a inserção de parte dos agricultores familiares e a 
constituição de territórios que são construídos localmente, a partir da atuação dos atores e sujeitos sociais.

Figura 1 - Localização dos municípios de Dracena e Regente Feijó no Estado de São Paulo, Brasil

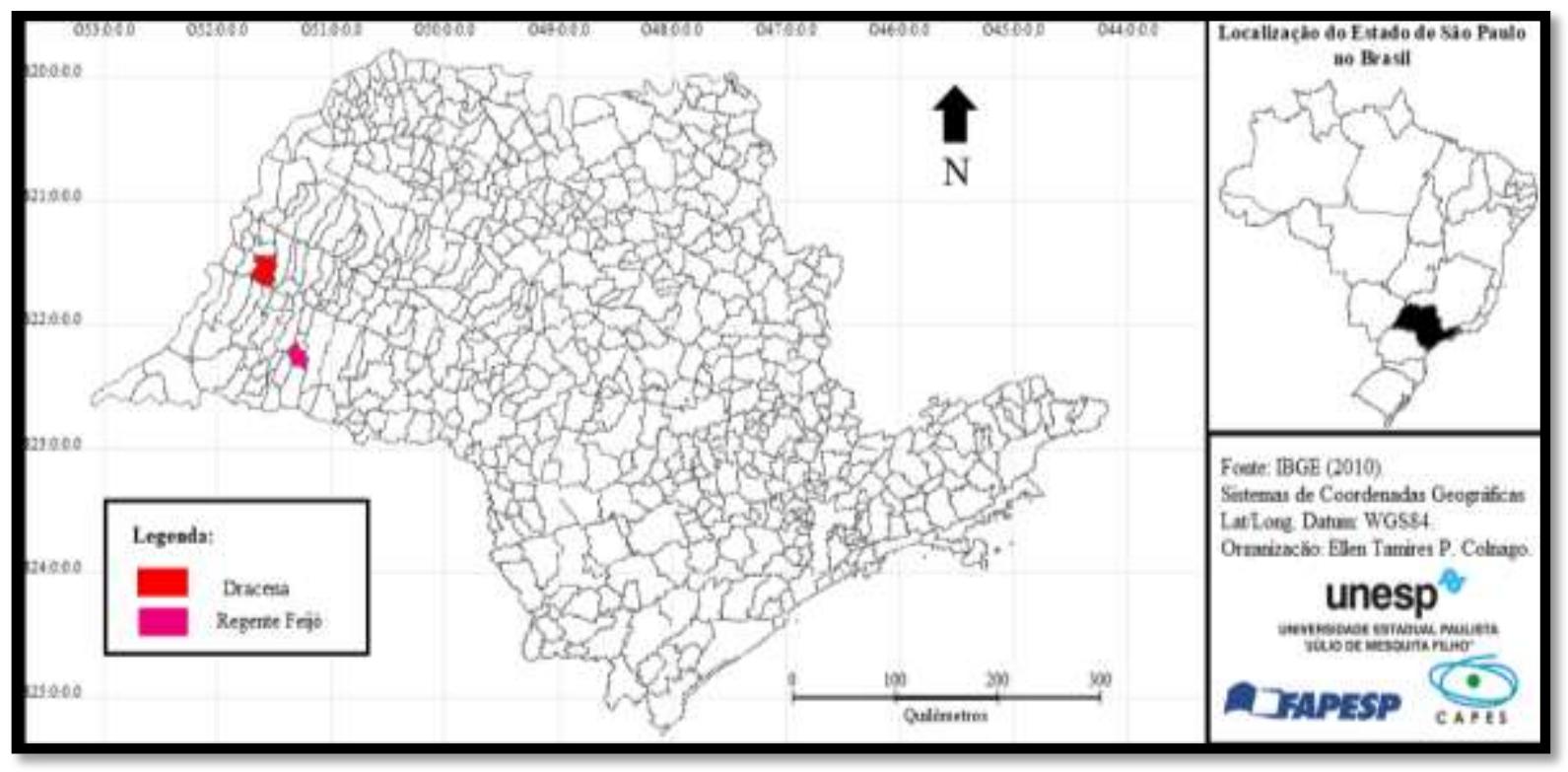

Fonte: organizada por Ellen Colnago a partir de IBGE (2010).

Para alcançarmos os objetivos propostos para a pesquisa, realizamos como procedimentos metodológicos: revisão de literatura em fontes bibliográficas, como livros, artigos, dissertações e teses, que abordaram, sob diferentes perspectivas, o processo de descentralização política e administrativa, o desenvolvimento territorial, os arranjos institucionais e a constituição e caracterização do PNAE; realização de entrevistas com roteiros pré-estruturados, com os atores sociais responsáveis em cada município pelo funcionamento do programa, e pela formação dos arranjos institucionais; e elaboração e aplicação de questionário junto aos agricultores familiares que entregam produtos no PNAE, no caso de Dracena, por meio da COOPADRA - Cooperativa dos Produtores Agropecuários de Dracena e, no caso de Regente Feijó, pela formação de um grupo informal.

Os questionários foram aplicados durante a pesquisa de campo, no ano de 2017, considerando uma amostra de $30 \%$ do total de 42 cooperados em Dracena, totalizando 13 produtores, e procuramos abarcar a diversidade produtiva existente entre os cooperados.

Em Regente Feijó, por outro lado, a amostra dos entrevistados correspondeu a uma porcentagem de $67 \%$ de 15 agricultores, totalizando 10 produtores, nos quais a aplicação dos questionários nos dois municípios buscou verificar a participação e a avaliação dos produtores no programa.

O artigo está dividido em duas partes, além desta introdução, das considerações finais e das referências. Na primeira parte, de cunho mais teórico, tratamos de compreender a 
formação dos arranjos institucionais e sua importância para a execução do PNAE, a partir das mudanças ocorridas no programa em virtude do processo de descentralização político e administrativo, e a aplicação da abordagem do desenvolvimento territorial.

Na segunda parte, contextualizamos os municípios de Dracena e Regente Feijó, a fim de exemplificar a importância do arranjo institucional formado para se alcançar resultados com o PNAE, considerando os atores sociais envolvidos quando se trata de beneficiar, por um lado, parte dos agricultores familiares que participam do PNAE e, do outro, os estudantes que consomem a alimentação escolar ofertada na escala local.

\section{A DESCENTRALIZAÇÃO POLÍTICA, A EMINÊNCIA DA ABORDAGEM TERRITORIAL E A FORMAÇÃO DOS ARRANJOS INSTITUCIONAIS NO CONTEXTO DE MUDANÇAS DO PNAE}

Entendido como uma política pública de Estado, o PNAE passou por diversas mudanças em sua estrutura e funcionamento desde sua criação em 1955, e as alterações feitas sob a ação do governo federal, nas décadas de 1990 e 2000, foram muito importantes.

Podemos afirmar que na década de 1980 a atuação do Estado brasileiro como principal coordenador e financiador das atividades produtivas no campo é diminuída em razão da crise econômica que o assola, fazendo alterar suas ações que passam a ser de forma minimalista, recebendo influências de instituições multilaterais (CHANG, 2008).

Novas propostas administrativas são colocadas para o Brasil e os demais países em desenvolvimento sob os estímulos neoliberais. A adoção de práticas descentralizadoras e a criação de políticas públicas voltadas ao desenvolvimento rural abrem novas perspectivas de atuação da ação estatal brasileira que, até então, era centralizada e prezava pelo apoio financeiro aos grandes produtores rurais, com a política de crédito rural, sustentando o projeto de modernização da agricultura (GONÇALVES NETO, 1997; HESPANHOL, 2007).

A crise econômica que se instaura no governo brasileiro, na década de 1980, aliada ao descontentamento da população frente ao regime militar, as incansáveis manifestações em busca da liberdade política e a atuação do Estado mínimo contribuíram para que no ano de 1988 fosse promulgada a nova Constituição Federal e, sob seu amparo, cria-se um regime descentralizado entre os governos federal, estadual e municipal (ALVES, 2003; ORTEGA, 2008).

Com a descentralização política e administrativa dos entes federados, os municípios passaram a ampliar suas ações, de modo a serem responsáveis pela operacionalização de determinadas políticas públicas, como o PNAE. 
Até o final dos anos 1980 o governo federal manteve a gestão centralizada do PNAE por meio da aquisição, num primeiro momento, de gêneros alimentícios de órgãos internacionais, através de convênios estabelecidos com os Estados Unidos, e posteriormente, de empresas nacionais e também internacionais presentes no território brasileiro (PEIXINHO, 2011; TURPIN, 2008).

Nesse período, era o governo federal que "[...] planejava os cardápios, adquiria os gêneros por processo licitatório, [...] e ainda se responsabilizava pela distribuição dos alimentos no território nacional" (ABRANDH e IBASE, 2012, p. 56).

Foi somente na década de 1990, após a promulgação da Constituição Federal em 1988 e de valorização das ações municipais, que o PNAE, com a institucionalização da lei n 8.913 (BRASIL, 1994), passou a ter sua gestão descentralizada.

Por meio dessa lei, o governo federal passou a valorizar a participação de representantes da administração pública local, os professores e os pais de alunos, entre outros, na formação do CAE - Conselho de Alimentação Escolar, responsável pela fiscalização e cumprimento do programa, e também a incentivar a presença de profissional de nutrição para a elaboração dos cardápios, respeitando a vocação agrícola regional e a preferência por produtos in natura (TURPIN, 2008).

A obrigatoriedade da contratação de profissional de nutrição nos municípios brasileiros só aconteceria em 2005, por meio da Resolução n 358 (BRASIL, 2005). Contudo, foi possível verificar que, desde a década de 1990, com a criação da Lei $n^{\circ} 8.913$, esse profissional já era requerido e podia ser contratado para trabalhar nas prefeituras municipais com a alimentação escolar.

O processo de descentralização do PNAE nos anos 1990 permitiu, deste modo, que setores municipais envolvidos com a educação e a alimentação escolar tivessem a responsabilidade de implementar o programa, utilizando os recursos repassados pelo governo federal.

Para tanto, caberia aos municípios a formação dos chamados arranjos institucionais, que nada mais seriam que "[...] o conjunto de regras, mecanismos e processos que definem a forma particular como se coordenam atores e interesses na implementação de uma política pública específica" (PIRES; GOMIDE, 2014, p. 20).

Tendo em vista os setores municipais envolvidos e que poderíamos denominar de atores sociais, ou seja, aqueles responsáveis pela execução de determinado programa governamental, a exemplo do PNAE, caberia a cada município frente à emancipação política que conquistara a possibilidade de gerenciar as políticas públicas e distribuir de maneira correta os recursos repassados pelo governo federal. 
O arranjo institucional formado localmente seria o mecanismo capaz de fazer a política pública acontecer (NICOLETTI, 2017), de modo que programas como o PNAE necessitam que se tenha em cada município uma organização desse tipo, para que se alcance pleno êxito em sua execução.

As mudanças que ocorreram no PNAE, contudo, não se limitaram à descentralização do programa nos anos 1990, pois com a institucionalização da lei oㅜ 11.947/ 2009, definiu-se que, pelo menos, $30 \%$ dos recursos repassados pelo FNDE - Fundo Nacional de Desenvolvimento da Educação, que passou a gerenciar os recursos do PNAE, a partir de 1998 (TURPIN, 2008), fossem utilizados para a aquisição de produtos originados da agricultura familiar.

As transformações ocorridas no programa no ano de 2009 associam-se diretamente à inserção do PNAE em uma política pública mais ampla estabelecida durante os governos de Luiz Inácio Lula da Silva, conhecida como Fome Zero, e uma perspectiva mais social que esteve presente durante as gestões dos governos do Partido dos Trabalhadores (PT).

Tal política buscava diminuir o problema da fome que assolava o país, para garantir o acesso aos alimentos por meio de políticas de segurança alimentar e nutricional (SAN). Nesse contexto, as escolas tornaram-se uma local chave para garantir a alimentação dos estudantes, e o PNAE, associado à entrada da produção familiar, contribuiu e contribui para se atingir esse objetivo (COLNAGO, 2018).

Desse modo, com a participação dos produtores rurais como um dos públicos do PNAE, houve a necessidade de que outros órgãos municipais associados à assistência técnica e extensão rural, por exemplo, também estivessem envolvidos com o programa, assim como as organizações coletivas (associações, cooperativas, sindicatos etc.) representativa desse segmento social.

Os arranjos institucionais locais criados para o funcionamento do programa tiveram, a partir dos anos 2000, a possibilidade de incorporação de novos atores sociais, permitindo que, na execução do programa fosse contemplado, por um lado, com uma alimentação saudável os estudantes das unidades de ensino, e por outro, se criasse um canal de comercialização para os agricultores familiares que participam do PNAE.

Contudo, essa não é uma realidade presente em todos os municípios brasileiros, já que a formação do arranjo institucional com a articulação de atores sociais necessários para a execução do PNAE depende da capacidade e do interesse de cada município em executálo (FARAH, 2001).

Os resultados do programa, deste modo, ficam dependentes da "[...] feição de cada localidade em que [é] e [são] [...] implantadas" (FARAH, 2001, p. 134), das políticas públicas, bem como do interesse assumido na escala local pelos atores sociais. Desse modo, cabe apontarmos que, juntamente com as transformações política da década de 
1990, que modificaram a execução do programa, e a preocupação com a segurança alimentar e nutricional que possibilitou a inserção da agricultura familiar nos anos 2000, tivemos, além destas mudanças, a influência da abordagem do desenvolvimento territorial sobre parte da ação governamental voltada ao espaço rural, em particular aquelas ações do Ministério do Desenvolvimento Agrário (MDA).

Sob esta perspectiva, o campo deixa de ser visto sob uma lógica setorial e produtivista, e passa a valorizar realidades até então não reconhecidas (GÓMEZ, 2006), como a presença de uma população rural importante a partir da agricultura familiar, e suas características relacionadas não só à produção agropecuária, mas de enraizamento em seus lugares de vida e de trabalho (WANDERLEY; FAVARETO, 2013).

Além disso, temas como "[...] a erradicação da pobreza rural, a questão do protagonismo dos atores sociais e sua participação política, o território como unidade de referência e a preocupação central com a sustentabilidade ambiental" (SCHNEIDER, 2004, p. 94), tornaram-se presentes nas concepções das políticas públicas.

A abordagem do desenvolvimento territorial considera as relações sociais, políticas, econômicas e institucionais construídas a partir da ação dos indivíduos, o ambiente em que estão inseridos, a integração entre campo e cidade, a presença de atores sociais e suas organizações coletivas, sendo o conteúdo deste espaço entendido como território (HESPANHOL, 2008; KAGEYAMA, 2008).

Implantado no Brasil, na década de 1990, sob a influência de agências multilaterais e tendo como exemplo as ações realizadas pelo Programa LEADER na Europa, o desenvolvimento territorial em nosso país foi disseminado de modo a valorizar a participação e a gestão local, com atores que impulsionem e fomentem resultados capazes de transformarem realidades econômicas e sociais.

Desse modo, visto as mudanças que o PNAE passou entre as décadas de 1990 e 2000, consideramos que o programa sofreu diretamente influencias dessa abordagem e pode também ser caracterizado como uma política que busca promover o desenvolvimento territorial.

Primeiramente, o PNAE é um programa que, desde a institucionalização da lei no 8.913/94, necessita de atores sociais locais para que possa ser implementado na escala local. Nos anos 2000 com a inserção da agricultura familiar, a partir da lei no 11.947/2009, o cenário de execução torna-se mais complexo, necessitando de novos atores, a participação de organizações coletivas de produtores rurais e a integração campo e cidade, por meio da produção de gêneros alimentícios dos agricultores e o abastecimento das unidades de ensino em cada município. 
Enfim, para a sua plena execução, o PNAE necessita da formação do arranjo institucional local, como já relatamos, e que também é algo requerido pelas políticas de desenvolvimento territorial.

Desse modo, o PNAE é um programa que mostra a capacidade de gestão local e a formação dos arranjos institucionais tornam-se fundamentais para que se alcance resultados positivos e possibilite assim a construção de territórios determinados pela ação de atores sociais. Ou seja, os territórios não são somente dados a partir dos limites físicos estabelecidos pelo Estado, mas também são construídos (CARRIERE; CAZELLA, 2006; FLORES, 2006), pelas condições locais de transformação, a partir da atuação dos arranjos institucionais, quando se trata do PNAE.

Entendida a importância da atuação dos atores sociais para a execução do PNAE na escala local, no próximo item trataremos de problematizar duas realidades empíricas que mostram a formação dos arranjos institucionais e a sua atuação diferenciada no desenvolvimento do programa, juntamente com a participação da agricultura familiar.

\section{A FORMAÇÃO DOS ARRANJOS INSTITUCIONAIS PARA A EXECUÇÃO DO PNAE NOS MUNICÍPIOS DE DRACENA E REGENTE FEIJÓ (SP)}

No subitem anterior, foi ressaltado as transformações das ações do Estado com relação à execução de políticas públicas, considerando os reflexos da descentralização e a eminência da abordagem do desenvolvimento territorial, e que influenciaram diretamente nas formas de execução do PNAE, ao longo dos anos de 1990 e 2000.

Neste subitem serão apresentadas duas realidades empíricas pesquisadas, ou seja, os municípios de Dracena e Regente Feijó, considerando as pesquisas de campo realizadas durante o percurso do mestrado, nos meses de fevereiro e março de 2017.

Foram entrevistados, utilizando roteiros estruturados, a nutricionista dos municípios, os agrônomos que trabalham com a assistência técnica e extensão rural, os membros do CAE, e a presidente da cooperativa em Dracena. As entrevistas foram gravadas e, depois de transcritas, foram analisadas de forma a se destacar as similitudes e diferenças em cada município, de modo a estabelecer um estudo comparativo entre eles, uma vez que analisar o PNAE em âmbito municipal é importante, pois permite "[...] conhecer o contexto onde a política acontece [...] para entender a dinâmica [da] política, os comportamentos dos atores e os efeitos das políticas públicas" (SECCHI, 2010, p. 61).

Realizar a análise do PNAE em escala local é direcionar-se para compreender "[...] quem são os atores sociais que fazem a política acontecer, quem são aqueles que, por suas atitudes, nos permitem compreender a constituição de territórios e a formação dos arranjos institucionais" (COLNAGO, 2018, p. 169). 
Desse modo, tratando-se da atuação dos atores sociais responsáveis pela implementação do PNAE e a formação do arranjo institucional, podemos afirmar que em Dracena temos a presença dos Agrônomos do EDR - Escritório de Desenvolvimento Rural e os da Casa da Agricultura; da nutricionista representando o Setor da Alimentação Escolar da Prefeitura Municipal; dos membros do CAE; e da presidente da COOPADRA - Cooperativa dos Produtores Agropecuários de Dracena, organização coletiva na qual os produtores participantes do programa são cooperados.

Em Regente Feijó o arranjo institucional é composto pela atuação dos agrônomos do EDR de Presidente Prudente e da Casa da Agricultura; dos membros da Cozinha Piloto, e da participação dos agricultores familiares por meio de um grupo informal.

A cozinha piloto em Regente Feijó concentra grande parte do preparo dos alimentos para as escolas do município. Ela é coordenada por três pessoas que exercem funções importantes, sendo a nutricionista, a chefe da alimentação escolar - porque em Regente Feijó além da nutricionista, existe essa profissional que coordena toda a alimentação escolar do município, e a secretária do chefe da alimentação escolar. Por isso, quando utilizarmos o termo cozinha piloto, estamos nos referindo a esses três profissionais que trabalham em conjunto e se auxiliam mutuamente para o funcionamento da alimentação escolar (COLNAGO, 2018, p. 192).

Existem algumas diferenças que marcam a atuação dos atores sociais presentes no arranjo institucional de cada município para a execução do PNAE como podemos constatar por meio das entrevistas realizadas nos dois municípios.

Em Dracena, podemos afirmar que a atuação de alguns atores sociais, envolvendo principalmente o agrônomo do EDR, a nutricionista e a presidente da cooperativa para executar a Lei no 11.947, ocorre desde o ano de 2009.

Nesse período (2009-2018), a presidente da cooperativa estava à frente da APRD Associação de Produtores Rurais de Dracena que, em 2015, se institucionalizou também como uma cooperativa a COOPADRA. O agrônomo do EDR intermediou as primeiras relações estabelecidas entre a nutricionista responsável pela alimentação escolar do município e a presidente da associação, de modo a fortalecer os vínculos de compra e entrega de produtos oriundos de uma pequena parte dos associados participantes (apenas dois produtores) da organização coletiva.

Desse modo, a cooperação estabelecida no município envolvendo o Setor da Alimentação Escolar e os produtores rurais, possibilitada pela atuação do agrônomo do EDR de Dracena, permitiu que no ano de 2010 fosse atingido o mínimo de 30\% dos recursos do FNDE destinado às compras da agricultura familiar. 
Em Regente Feijó, por outro lado, o alcance do mínimo de 30\% dos recursos repassados pelo FNDE em compras dos produtores rurais só foi atingido no ano de 2015, em razão da não organização dos atores sociais locais, ou seja, entre a agrônoma da Casa da Agricultura e os funcionários da Cozinha Piloto, tendo um pequeno número de produtores rurais participantes, entregando poucos produtos e não atingindo os $30 \%$ exigidos por lei, necessários para alavancar o programa na escala municipal.

O diretor do EDR de Presidente Prudente, do qual o município de Regente Feijó faz parte, em 2009 divulgou o programa, todavia coube aos atores locais presentes em Regente Feijó a busca e o interesse por executar o PNAE, e que não obteve resultados positivos até o ano de 2015.

O alcance do mínimo de $30 \%$ dos recursos do FNDE para a aquisição de produtos da agricultura familiar foi atingido apenas no ano de 2015 em Regente Feijó, por que houveram modificações na execução do programa na escala local, a partir de 2013, associadas à entrada de novos atores sociais que possibilitaram alavancar a execução do PNAE, como o próprio EDR de Presidente Prudente que, neste período, enviou um sociólogo da CODEAGRO - Coordenadoria de Desenvolvimento dos Agronegócios, para o município de Regente Feijó para fomentar o programa.

O sociólogo designado pelo EDR, junto com a agrônoma da Casa da Agricultura e os membros da Cozinha Piloto do município de Regente Feijó, organizou um grupo informal de produtores rurais em 2013, o que possibilitou o atendimento da Lei no 11.947/2009 em 2015.

Os agrônomos da Casa da Agricultura dos dois municípios pesquisados também fizeram um trabalho importante ligado à inserção dos produtores rurais no PNAE, trabalhando diretamente com a associação APRD de produtores, no caso de Dracena, e com o grupo informal, no caso de Regente Feijó.

Em Dracena, a principal demanda ocorreu na associação que necessitava dos agrônomos para auxiliar na elaboração dos primeiros projetos de venda ao PNAE, ação que formaliza a compra de produtos dos agricultores familiares. Já em Regente Feijó, a agrônoma da Casa da Agricultura atuou de modo a fomentar a criação do grupo informal em 2013, reunindo os produtores para participar do PNAE.

A Casa da Agricultura em Regente Feijó foi a responsável pela execução do primeiro projeto de venda, seguindo até os dias atuais com essa atribuição, além do que é responsável pela composição anual deste grupo informal que tende a ser integrado, em sua maioria, pelos mesmos produtores rurais, acompanhando também as reuniões feitas no início de ano junto com os funcionários da Cozinha Piloto e um produtor representante do grupo informal. Nestas reuniões são discutidos e decididos os tipos, as quantidades e os preços dos produtos a serem entregues pelos agricultores familiares participantes do PNAE. 
A atuação da agrônoma da Casa da Agricultura no município de Regente Feijó mostra, portanto, a total dependência que existe para a elaboração dos projetos de venda e tramites de comercialização envolvendo a participação dos produtores no PNAE, revelando a importância que essa instituição tem na escala local para a inserção de número limitado de agricultores no programa.

Em Dracena, por sua vez, quando se trata das reuniões feitas para decidir os tipos, as quantidades e os preços dos produtos a serem pagos aos agricultores familiares, participam a nutricionista e a presidente da cooperativa, não havendo um envolvimento do agrônomo da Casa da Agricultura de Dracena, já que, diferentemente dos produtores de Regente Feijó, em Dracena a organização coletiva tem maior autonomia representada na figura da presidente para tomar decisões e lidar com questões burocráticas, já que ela também é presidente do CAE.

Tanto em Dracena como em Regente Feijó a atuação dos profissionais do Setor da Alimentação Escolar, representado pela nutricionista no primeiro município e pelos funcionários da Cozinha Piloto no segundo, mostrou aceitabilidade com relação às compras dos produtos oriundos da agricultura familiar para atender as unidades de ensino.

Os valores das compras dos produtores rurais em Dracena, desde o ano de 2010, atingem os $30 \%$ dos recursos do FNDE exigidos por lei, de modo que essa porcentagem ampliou-se, chegando a alcançar em 2014 o total de 50\%, em virtude do complemento de recursos repassado pelo governo municipal, e que, portanto, possibilitava que uma maior parte dos valores repassados pelo governo federal fosse utilizada para compras da agricultura familiar.

Contudo, desde 2015 as compras da alimentação escolar no município de Dracena não têm mais a contribuição dos recursos do governo municipal, em razão da crise financeira que atingiu a prefeitura municipal, para adquirir uma porcentagem maior, permanecendo atualmente no mínimo de 30\% de acordo com a Lei de 2009.

Em Regente Feijó, por outro lado, desde que se conseguiu atingir os 30\% em 2015, a porcentagem de compra tem aumentado, em razão da participação dos recursos municipais que, por sua vez, é empregado para adquirir produtos não perecíveis, deixando um valor maior dos recursos federais para a aquisição de produtos in natura da agricultura familiar.

Em relação ao CAE, tanto em Dracena como em Regente Feijó, existe a formação deste conselho como estabelece a legislação. Contudo, quanto se trata do trabalho realizado, podemos afirmar que no primeiro município existe uma participação mais efetiva dos membros do conselho voltada para a fiscalização dos recursos enviados pelo governo federal à prefeitura municipal, e um acompanhamento da alimentação nas escolas, por meio 
de visitas regulares, enquanto que no segundo município a única função do CAE limita-se a prestação de contas.

Isso demonstra o descumprimento de algumas atribuições do CAE de Regente Feijó, e que também permeia a realidade de muitos outros municípios brasileiros, assim como a não existência de meios de transportes para facilitar o deslocamento dos membros para realizar o acompanhamento e a fiscalização nas escolas. Ou seja, o CAE quando funciona nos municípios é porque alguns membros têm iniciativa própria e buscam superar as barreiras impostas para realizar a fiscalização da alimentação escolar, como no caso de Dracena, em que existe um acompanhamento assíduo nas unidades de ensino, porque a presidente do conselho utiliza seu carro particular para realizar as visitas.

Isso mostra, segundo Nicoletti (2017), que a forma institucional alcançada por um programa local depende não somente de quem a formula, e sim muito de quem o executa localmente.

A fase da implementação de uma política pública se trata do momento em que "[...] se formam os arranjos institucionais [...] [e] pode-se analisar esse arranjo e compreender o que ele é capaz de promover, se consegue oferecer sustentação à política pública ou se mantém o programa incólume" (NICOLLETTI, 2017, p. 36).

Essas condições também se manifestam de forma a compreender a atuação de atores sociais locais na constituição de territórios e o exercício da abordagem territorial, já que as forças locais são responsáveis pelos efeitos das políticas públicas a partir da formação dos arranjos institucionais (COLNAGO, 2018).

Contudo, é importante ressaltar que mesmo que uma política pública tenha resultados positivos e que para isso dependa das ações que são constituídas localmente, a atuação do Estado se faz necessária em relação às demandas das etapas da implementação da política pública (NICOLETTI, 2017).

Se a Constituição Federal de 1988, através do processo de descentralização política e administrativa, por um lado permitiu a participação da sociedade na implementação das Políticas Públicas e, por outro, trouxe problemas na execução dos programas governamentais associados à própria participação, ausência de recursos e despreparo das instituições locais (FORNAZIER, 2015; HESPANHOL, 2007).

Além disso, a falta de profissionais para conduzir os programas, "[...] também é outro fator preocupante, uma vez que a ação territorial fica à mercê da boa vontade de quem queira executá-la, não existindo, deste modo, condições para efetuá-la em todos os territórios e municípios" (COLNAGO, 2018, p. 75).

O resultado de uma política pública depende muito da ação dos atores locais e do envolvimento e comprometimento dos mesmos, conforme o processo de descentralização política e administrativa influenciou nas mudanças de operacionalização do PNAE. Contudo, 
- Estado deveria se fazer mais presente através do oferecimento de corpo técnico qualificado para orientar os atores sociais envolvidos e também fiscalizar de perto a execução do programa, já que o mesmo também repassa os recursos federais que podem ser aplicados na alimentação escolar.

Sua fiscalização é falha, uma vez que o controle que se tem sobre o funcionamento do PNAE ocorre somente através das informações que são repassadas pelas prefeituras no site do FNDE - Fundo Nacional de Desenvolvimento da Educação.

As prefeituras locais, nos casos em que não se empenham, deveriam se envolver mais, pois podem e devem complementar financeiramente os recursos utilizados para a alimentação escolar. Além disso, devem oferecer total apoio às Casas de Agricultura, que dão assistência técnica aos produtores rurais no Estado de São Paulo, e ao profissional de nutrição para que o programa tenha seu pleno funcionamento, em termos de aquisição de produtos da agricultura familiar e a garantia de uma alimentação saudável.

De qualquer modo, a descentralização das políticas públicas, entre elas o PNAE, enfrenta dificuldades de execução na maioria das localidades brasileiras, pois elas têm baixo nível de organização e dificuldade de acesso a determinados serviços públicos que impedem a adoção de uma abordagem territorial que preze pela ação dos atores sociais (SCHEJTMAN, 1997).

Os municípios de Dracena e Regente Feijó, mesmo que no caso do segundo haja algumas falhas na atuação do CAE, possuem condições de operacionalização do programa que são possíveis graças ao envolvimento dos atores sociais em cada localidade, que permite, nas condições particulares de cada um, o funcionamento do PNAE.

Quanto à participação dos produtores rurais no arranjo institucional local, podemos afirmar que em Dracena, em virtude da presidente da Coopadra exercer um papel de liderança e buscar novas oportunidades e conhecimentos, os produtores participam não somente do PNAE, mas de outras políticas públicas, como o Microbacias II do governo do Estado de São Paulo.

O Microbacias II é um programa criado pelo governo do Estado de São Paulo, com execução desde 2011. O objetivo principal desse programa é proporcionar aos agricultores familiares o acesso ao mercado, através do melhoramento da competividade daqueles organizados em associações ou cooperativas, segundo recursos provenientes do governo do estado, e de acordos firmados com o Banco Mundial, as prefeituras e as organizações formais dos produtores rurais (SÃO PAULO, 2017).

Foi através desse programa que a APRD pôde também formar uma cooperativa - a COOPADRA -, e adquirir, assim, equipamentos como o miniprocessamento de legumes e hortaliças, a despolpadeira de frutas e as máquinas para pasteurização de leite, agregando 
valor aos produtos in natura, que podem ser comercializados não somente por meio das políticas públicas como o PNAE e o PPAIS - Programa Paulista de Agricultura de Interesse Social, mas também em outros mercados, participando dos processos de licitação de compra.

Em Regente Feijó a ausência de uma organização coletiva formal dos produtores rurais diminui as possibilidades de os produtores alavancarem e conseguirem participar de outras políticas públicas, além do PNAE, e também a comercialização de produtos limita-se a ser in natura, já que investirem sozinhos em produtos com agregação de valor torna-se muito caro e inviável para a maioria.

Deste modo, apesar de ter nos dois municípios atores sociais que cooperam para que o PNAE funcione através da formação do arranjo institucional, tanto em Dracena como em Regente Feijó existem realidades distintas de desenvolvimento do programa, que manifestam a criação de territórios que tem suas próprias características e permitem, portanto, afirmar que o envolvimento dos atores e sujeitos sociais é o que faz o programa acontecer, e compreender a realidade de execução da política pública na escala local.

\section{CONSIDERAÇÕES FINAIS}

Podemos destacar neste artigo que as mudanças políticas ocorridas no final da década de 1980, com a promulgação da Constituição Federal de 1988, e a eminência da abordagem territorial entre a década de 1990 e os anos 2000, afetaram o modo de atuação do Estado brasileiro associado à implementação de políticas públicas, entre elas o PNAE.

O PNAE, na década de 1990, por meio da Lei no 8.913/94 passa a ter sua gestão descentralizada, de modo que a criação do CAE para acompanhamento e fiscalização das ações do programa na escala local e a presença de um profissional da área da nutrição são requeridos. Se começa, portanto, a desenhar nos municípios a necessidade da formação dos arranjos institucionais para a implementação do PNAE, por meio da atuação dos atores sociais.

Nos anos 2000, em razão da introdução da agricultura familiar como um dos públicos do programa, por meio da Lei no 11.947/2009, a formação dos arranjos institucionais passa a ser algo cada vez mais requerido e fundamental, necessitando da participação de novos atores para representarem os produtores rurais, para fomentarem a execução correta do programa, e a compra de, no mínimo, 30\% dos recursos destinados pelo (FNDE) à alimentação escolar.

Além disso, a própria alteração do PNAE nos anos 2000, com a entrada da agricultura familiar, mostra a valorização da integração entre o campo com a produção de gêneros alimentícios e a cidade com a necessidade de abastecimento das unidades de ensino. 
Prioriza-se também a gestão institucional em que há a participação dos atores sociais que executam o programa, aspectos que são valorizados pela abordagem do desenvolvimento territorial.

Visto que as influências externas nas políticas do Brasil afetaram diretamente o espaço rural com a abordagem territorial, as transformações políticas do final dos anos 1980 e na década de 1990 também cooperaram para que o PNAE fosse alterado e fosse necessária a formação de um arranjo institucional para executá-lo.

Podemos constatar que em Dracena há a participação de todos os atores sociais de modo articulado para fomentar o programa, o que justifica os resultados positivos alcançados com o PNAE neste município, em razão do arranjo institucional formado.

Em Regente Feijó ainda existem algumas falhas como na própria atuação do CAE e na ausência de uma organização coletiva formal dos produtores rurais. Todavia, temos uma articulação estabelecida pelos atores locais, do Setor da Alimentação Escolar e da Casa da Agricultura, que permite a constituição de um grupo informal de produtores que entrega gêneros alimentícios para a alimentação escolar, e que vem alcançando resultados positivos e compras acima dos $30 \%$ estabelecidos em lei.

Assim, se verifica que a legislação do programa é a mesma para todos os municípios brasileiros e determinada pelo governo federal, porém só se tem real dimensão do desenvolvimento do programa e da conquista dos seus objetivos quando analisamos na escala local a sua execução, como fizemos nos municípios de Dracena e Regente Feijó. Desse modo, podemos afirmar que o PNAE só funciona e atinge os seus objetivos quando ocorre a formação de um arranjo institucional local, constituído por atores sociais que, de forma articulada, trabalham e se organizam para a execução da política pública.

\section{REFERÊNCIAS}

ABRANDH - AÇÃO BRASILEIRA PELA NUTRIÇÃO E DIREITOS HUMANOS; IBASE INSTITUTO BRASILEIRO DE ANÁLISES SOCIAIS E ECONÔMICAS. Projeto agricultura familiar, alimentação escolar e a realização do direito humano à alimentação adequada. Brasília, DF: FNDE/MEC, 2012. Relatório de pesquisa.

ALVES, E. Descentralização de políticas públicas no Brasil: da crise do Estado ao neoliberalismo dos anos 90. In: ENCONTRO DE ECONOMISTAS DA LÍNGUA PORTUGUESA, 5., 2003. Recife, PE. Anais [...]. Recife: CORECON, 2003. p. 5-7.

ALVES, A. F.; GUIVANT, J. S. O que há além do endógeno e exógeno nas pesquisas sobre o desenvolvimento rural? In: SAQUET, M. A.; SANTOS, R. A. (org.). Geografia agrária, território e desenvolvimento. São Paulo: Expressão Popular, 2010. p. 89-106.

BRASIL. Lei no 8.913, de 12 de julho de 1994. Dispõe sobre a municipalização da merenda escolar. Brasília, DF: Congresso Nacional, 1994. Disponível em: http://www.planalto.gov.br/ccivil_03/leis/L8913.htm. Acesso em: 12 jun. 2018. 
Lei no 11.947, de 16 de junho de 2009. Dispõe sobre o atendimento da alimentação escolar e do Programa Dinheiro Direto na Escola aos alunos da educação básica; [...]. Brasília, DF: Congresso Nacional, 2009. Disponível em: http://www.planalto.gov.br/ccivil_03/_ato2007-2010/2009/lei/l11947.htm. Acesso em: 23 maio 2018.

Ministério da Educação. Fundo Nacional de Desenvolvimento da Educação.

$\overline{R e s o l u c ̧ a ̃ o ~} n^{\circ}$ 358, de 18 de maio de 2005. Dispõe sobre as atribuições do Nutricionista no âmbito do Programa de Alimentação Escolar (PAE) e dá outras providências. Brasília, DF: FNDE, 2005. Disponível em:

https://www.fnde.gov.br/fndelegis/action/UrlPublicasAction.php?acao=getAtoPublico\&sgl_tip $0=R E S \&$ num_ato $=00000358 \& \mathrm{seq} \_$ato $=000 \& \mathrm{vlr}$ ano $=2005 \& \mathrm{sg} \mid$ lorgao $=C F N / E F E P L$. Acesso em: 29 out. 2017.

CARRIERE, J. P.; CAZELLA, A. A. Abordagem introdutória ao conceito de desenvolvimento territorial. Eisforia, Florianópolis, v. 4, p. 23-47, dez. 2006.

COLNAGO, E. T. P. Desenvolvimento territorial e alimentação escolar: estudo comparativo do Programa Nacional de Alimentação Escolar (PNAE) em Dracena e Regente Feijó (SP). 2018. Dissertação (Mestrado em Geografia) - Faculdade de Ciência e Tecnologia, Universidade Estadual Paulista, Presidente Prudente, 2018.

CHANG, H. J. Maus samaritanos: o mito do livre comércio e a história secreta do capitalismo. Rio de Janeiro: Elsevier: Campus, 2008.

FARAH, M. F. S. Parcerias, novos arranjos institucionais e políticas públicas no nível local de governo. Revista de Administração Pública, Rio de Janeiro, p.119-144, 2001.

FORNAZIER, A. O papel do município nas políticas públicas de desenvolvimento territorial rural no Brasil. Revista em Gestão, Inovação e Sustentabilidade, Brasília, v. 1, n. 1, p. 148-168, dez. 2015.

FLORES, M. A identidade cultural do território como base de estratégias de desenvolvimento: uma visão do estado da arte. 2006. Disponível em: https://static.fecam.net.br/uploads/28/arquivos/4069_FLORES_M_Identidade_Territorial_co mo_Base_as_Estrategias_Desenvolvimento.pdf. Acesso em: 13 jan. 2019.

GÓMEZ, J. R. M. Desenvolvimento em (des)construção: narrativas escalares sobre o desenvolvimento territorial rural. 2006. Tese (Doutorado em Geografia) - Faculdade de Ciências e Tecnologia, Universidade Estadual Paulista, Presidente Prudente, 2006.

GONÇALVES NETO, W. Estado e agricultura no Brasil: política agrícola e modernização econômica brasileira, 1960-1980. São Paulo: Hucitec, 1997.

HESPANHOL, A. N. O desenvolvimento do campo no Brasil. In: FERNANDES, B. M; MARQUES, M. I. M; SUZUKI, J. C (org.). Geografia agrária: teoria e poder. São Paulo: Expressão Popular, 2007. p. 271-287.

Modernização da agricultura e desenvolvimento territorial. IV Encontro Nacional de Grupos de Pesquisa, 2008, São Paulo. In: ENCONTRO NACIONAL DE GRUPOS DE PESQUISA- ENGRUP, 4., 2008, São Paulo. Anais [...]. São Paulo: USP, 2008. p. 370-392.

HESPANHOL, R. A. M. A adoção da perspectiva territorial nas políticas de desenvolvimento rural no Brasil. Campo-Território: Revista de Geografia Agrária, Uberlândia, MG, v. 5, n. 10, p. 123-147, ago. 2010.

IBGE. Bases e referenciais. 2010. Disponível em: https://mapas.ibge.gov.br/bases-ereferenciais/bases-cartograficas/malhas-digitais.html. Acesso em: 21 nov. 2018.

KAGEYAMA, A. A. Desenvolvimento rural: conceitos e aplicações ao caso brasileiro. Porto Alegre, RS: UFRGS, 2008. 
NICOLETTI, M. P. Análise da implementação do Programa Nacional de Alimentação Escolar - PNAE no município de Natal-RN a partir dos arranjos institucionais locais. 2017. Dissertação (Mestrado em Estudos Urbanos) - Universidade Federal do Rio Grande do Norte, Natal, 2017.

ORTEGA, A. C. Territórios deprimidos: desafios para as políticas de desenvolvimento rural. Campinas: Alínea, 2008.

PEIXINHO, A. M. L. Um resgate histórico do Programa Nacional de Alimentação

Escolar (PNAE). 2011. Dissertação (Mestrado Profissional em Ensino em Ciências da Saúde) - Universidade Federal de São Paulo, São Paulo, 2011.

PIRES, R. R. C.; GOMIDE, A. Capacidades estatais e democracia: arranjos institucionais de políticas públicas. Rio de Janeiro: IPEA, 2014.

SÃO PAULO (Estado). Coordenadoria de Assistência Técnica e Integral (CATI).

Microbacias II: acesso ao mercado. 2017. Disponível em:

http://www.cati.sp.gov.br/microbacias2/. Acesso em: 22 nov. 2018.

SCHEJTMAN, A. La questión urbana em el desarrollo rural: elementos regionais para América Latina y el Caribe, 1997, p. 1-8. In: SEMINÁRIO INTERNACIONAL: Interrelación Rural-Urbana y Desarrollo Descentralizado, Taxco, México, 1997 (FAO- Borrador). Anais [...]. Taxco, México: FAO- Borrador, 1997.

SCHNEIDER, S. A. abordagem territorial do desenvolvimento rural e suas articulações externas. Sociologias, Porto Alegre, RS, v. 11, p. 88-125, 2004.

SECCHI, L. Políticas públicas: conceitos, esquemas de análise: casos práticos. São Paulo: Cengange Learning, 2010.

TURPIN, M. E. A alimentação escolar como vetor de desenvolvimento local e garantia de segurança alimentar e nutricional. 2008. Dissertação (Mestrado em Economia) Universidade Estadual de Campinas, Campinas, SP, 2008.

WANDERLEY, M. N. B.; FAVARETO, A. A singularidade do rural brasileiro: implicações para as tipologias territoriais e a elaboração de políticas públicas. In: MIRANDA, C.; SILVA, H. (org.). Concepções da ruralidade contemporânea: as singularidades brasileiras. Brasília, DF: IICA, 2013. p. 413-463.

Recebido: janeiro de 2019. Aceito: maio de 2019. 